\title{
Studies on Ethanol Production from Agricultural By-Product
}

\author{
A. KOLI, B. PATIL ${ }^{*}$ and F. PAREKH \\ Department of Biotechnology, H.P.T Arts and R.Y.K. Science College, \\ Nashik- 422005, India \\ aakashkoli55@gmail.com
}

Received 7 February 2015 / Accepted 13 February 2015

\begin{abstract}
The research takes into consideration the chances of production of ethyl alcohol which is an important component in the beverage industry, as a solvent, antiseptic and fuel produced by fermentation of sugars. The industrial by-product used for the study was a mixture of Indian elite lines of maize cobs and groundnut shells. The mixtures were taken in various concentrations. The optimal glucose yield at a particular acid concentration was determined using varied concentrations of sulphuric acid $\left(\mathrm{H}_{2} \mathrm{SO}_{4}\right)$. This acid concentration was further used to study the dependence of glucose yield on the temperature. The end product (glucose) was hydrolysed and filtered to serve as a substrate for S.cerevisiae which could yield sufficient amount of ethanol within four hours.
\end{abstract}

Keywords: Glucose, Alcohol, Fermentation, Hydrolysis, S.cerevisiae

\section{Introduction}

Production of glucose from biomass is a common process of saccharification employed in the industries. Consumption of maize in India is 16 million tons per year. The advent in technology has led to discharge of large amounts of agricultural wastes, which adversely harms the environment if not disposed off $f^{1,2}$. Researchers are finding alternatives to the wise use of such wastes for the production of useful products such as the current study on the production of ethanol. Ethanol is extensively used as a bio fuel in some countries such as Brazil, as a solvent in industries, in domestic burners for cooking and heating.

Maize cobs (Zea mays) and groundnut shells (Arachis hypogaea) are independently used for the production of fuel, but this research shows that a mixture of both in an equivalent ratio gives better results. They possess high ratios of basic constituents namely cellulose and hemicelluloses which are converted to lignocelluloses and serve as a best source of energy. Ethanol produced from renewable sources is an attractive petrochemical feedstock ${ }^{3}$. The present study investigates the effect of auto hydrolysis pre-treatment method on glucose production from maize cobs and groundnut shells subjected to hydrolysis and high temperature conditions. 


\section{Experimental}

Maize cobs and groundnut shells were collected in polyethylene bags from the local market in Nashik. They were washed and cleaned thoroughly with distilled water and sun dried for about 2 weeks so that they can be grinded well.

A disc grinder was used to grind the mixture into very small sizes. These particles were filtered to get a homogenous powdered form of the mixture. $20 \mathrm{~mL}$ of diethyl ether was added to $10 \mathrm{~g}$ of sample in a flask so as to remove the extractives and the left over was washed twice with distilled water. Further, cellulose and hemicelluloses were dissolved in $20 \mathrm{~mL}$ of $\mathrm{H}_{2} \mathrm{SO}_{4}$ leaving behind lignin as a solid precipitate.

\section{Optimisation of acid concentration and the substrate conc. for maximum yield}

So as to optimise the individual quantities of maize cobs and groundnut shells for the optimum quantity of ethanol production, these were taken in the ratio of 1:1, 1:2, 2:1 and 3:1 ${ }^{4}$. The different $\mathrm{H}_{2} \mathrm{SO}_{4}$ concentrations taken into experimental consideration were $3.5 \mathrm{M}, 4 \mathrm{M}, 4.5 \mathrm{M}$ and $5 \mathrm{M}^{5,6}$. The production was started using $3 \mathrm{M}$ acid concentration in a $100 \mathrm{~mL}$ conical flask at room temperature, under $100 \mathrm{rpm}$ continuous stirring which serve as a reactor. The reaction was allowed to progress for $4 \mathrm{~h}$. Small quantities of the hydrolysed samples were collected at intervals, filtered and analysed using a refractometer. The entire procedure was repeated for different acid concentrations and the hydrolyzed samples were analyzed.

The optimum acid concentration was found to be $4.5 \mathrm{M}$, which was used further for different ratios of maize cobs and groundnut shells (1:1, 1:2, 2:1 and 3:1). This filtrate was screened for glucose and the best ratio was determined. Using the best ratio 3:1 for maize cobs and groundnut shells and acid concentration $4.5 \mathrm{M}$, the effect of temperature on hydrolysis was scrutinised using a water bath at temperatures namely $40{ }^{\circ} \mathrm{C}, 50{ }^{\circ} \mathrm{C}, 60{ }^{\circ} \mathrm{C}$, $70{ }^{0} \mathrm{C}$ and $80{ }^{0} \mathrm{C}^{7}$. The reaction was carried out at each temperature for $4 \mathrm{~h}$. The resulting hydrolysed sample was filtered, leaving behind a high glucose containing filtrate. This acted as a substrate for fermentation.

\section{Bioprocess for final ethanol production}

The substrate was inoculated with S.cerevisiae culture, which would in turn ferment glucose in the substrate and produce ethanol. The autoclaved conical flask was tightly sealed to avoid any contaminants entering the fermentation media. The reaction was allowed to progress for $3 \mathrm{~h}$. Samples were taken after every half an hour for the estimation of glucose and ethanol concentration. Total hydrolysis of glucose ${ }^{8}$ was carried out for higher production of ethanol. The entire fermentation process resulted in ethanol production which was recovered using lab scale batch distillation. Confirmatory chemical tests were carried out to validate that the distillate was ethanol.

\section{Results and Discussion}

\section{Optimisation of acid and substrate concentration}

In case of acid hydrolysis of maize cobs and groundnut shells, it showed that the glucose concentration increased with time (Table 1). Higher glucose concentration was noted for $4.5 \mathrm{M}$ of acid concentration. The glucose yield was observed to elevate from 0 to $0.63 \mathrm{~g} / \mathrm{cm}^{3}$ at this acid concentration. The glucose concentration was observed to decrease at $5 \mathrm{M}$ acid concentration, probably due to formation of other intermediates at higher acid concentration which leads to decreased glucose yield. 
Table 1. Glucose yield for hydrolysis at varying $\mathrm{H}_{2} \mathrm{SO}_{4}$ concentrations

\begin{tabular}{cccccc}
\hline \multirow{2}{*}{ Time, min } & \multicolumn{5}{c}{ Glucose yield, $\mathrm{g} / \mathrm{cm}^{3}$} \\
\cline { 2 - 6 } & $\begin{array}{c}\text { 3 M acid } \\
\text { conc. }\end{array}$ & $\begin{array}{c}\text { 3.5 M acid } \\
\text { conc. }\end{array}$ & $\begin{array}{c}4 \mathrm{M} \text { acid } \\
\text { conc. }\end{array}$ & $\begin{array}{c}4.5 \mathrm{M} \text { acid } \\
\text { conc. }\end{array}$ & $\begin{array}{c}5 \mathrm{M} \text { acid } \\
\text { conc. }\end{array}$ \\
\hline 0 & 0 & 0 & 0 & 0 & 0 \\
15 & 0.03 & 0.04 & 0.05 & 0.06 & 0.02 \\
30 & 0.10 & 0.13 & 0.15 & 0.17 & 0.11 \\
60 & 0.19 & 0.21 & 0.23 & 0.25 & 0.22 \\
90 & 0.33 & 0.35 & 0.38 & 0.40 & 0.30 \\
120 & 0.40 & 0.46 & 0.48 & 0.56 & 0.42 \\
150 & 0.45 & 0.49 & 0.54 & 0.63 & 0.50 \\
\hline
\end{tabular}

Table 2. Glucose yield for different ratios of maize cobs and groundnut shells

\begin{tabular}{ccccc}
\hline \multirow{2}{*}{ Time, min } & \multicolumn{4}{c}{ Glucose yield, g/cm ${ }^{3}$} \\
\cline { 2 - 5 } & $1: 1$ & $1: 2$ & $2: 1$ & $3: 1$ \\
\hline 0 & 0 & 0 & 0 & 0 \\
15 & 0.03 & 0.06 & 0.01 & 0.09 \\
30 & 0.12 & 0.13 & 0.10 & 0.17 \\
60 & 0.20 & 0.22 & 0.18 & 0.28 \\
90 & 0.31 & 0.34 & 0.27 & 0.43 \\
120 & 0.45 & 0.49 & 0.40 & 0.58 \\
150 & 0.52 & 0.55 & 0.47 & 0.70 \\
\hline
\end{tabular}

The optimum acid concentration for hydrolysis was estimated to be $4.5 \mathrm{M}$. This concentration was used to determine the ratio of maize cobs to groundnut shells for maximum glucose yield. The ratios taken into consideration were 1:1, 1:2, 2:1 and 3:1. The glucose yield was estimated to increase for 3:1 ratio (Table 2) of maize cobs to groundnut shells from 9 to $0.70 \mathrm{~g} / \mathrm{cm}^{3}$. The glucose yield was observed to drastically reduce at the ratio 1:2 when compared to other ratios. This is probably due to high amount of groundnut shells that possess structures that are less accessible to acid attack. Further, acid hydrolysis of this mixture at varying temperature, with $4.5 \mathrm{M} \mathrm{H}_{2} \mathrm{SO}_{4}$ concentration caused an increase in glucose yield with time (Table 3).

Table 3. Glucose yield for hydrolysis of maize cobs and groundnut shells at 3:1 ratio, $4.5 \mathrm{M}$ $\mathrm{H}_{2} \mathrm{SO}_{4}$ concentration and varying temperature

\begin{tabular}{ccccc}
\hline \multirow{2}{*}{ Time, min } & \multicolumn{4}{c}{ Glucose yield, g/ $/ \mathrm{cm}^{3}$} \\
\cline { 2 - 5 } & $50{ }^{0} \mathrm{C}$ & $60{ }^{0} \mathrm{C}$ & $70{ }^{0} \mathrm{C}$ & $80{ }^{0} \mathrm{C}$ \\
\hline 0 & 0 & 0 & 0 & 0 \\
15 & 0.10 & 0.22 & 0.28 & 0.33 \\
30 & 0.21 & 0.53 & 0.39 & 0.68 \\
60 & 0.54 & 0.64 & 0.58 & 0.93 \\
90 & 0.79 & 0.71 & 0.76 & 1.20 \\
120 & 0.82 & 0.83 & 0.87 & 1.33 \\
150 & 0.88 & 0.90 & 1.02 & 1.46 \\
\hline
\end{tabular}

The glucose yield was estimated to elevate at $80{ }^{0} \mathrm{C}$ from 0 to $1.46 \mathrm{~g} / \mathrm{cm}^{3}$. This concludes that the glucose yield is highest at moderate acid concentration and high temperature range. During the entire process, the glucose concentration went on decreasing while the ethanol concentration went on increasing; denoting the fact that during fermentation S.cerevisiae utilized glucose as a source of energy and carbon and in turn produced ethanol as a product. 


\section{Confirmatory tests for ethanol}

Different tests were carried out to ascertain that the distillate formed as a fermentation product of maize cobs and groundnut shells was ethanol. The confirmatory tests include testing the absorbance of the distillate using a double beam spectrophotometer (Shimadzu, UV-2450). This demonstrates to be a confirmatory test as ethanol shows a maximum absorbance value at $220 \mathrm{~nm}$.

As fermentation proceeded, a depression in the glucose concentration and converse increase in the ethanol production was observed as in Table 4. This was another confirmatory test used to ensure that the distillate obtained was ethanol.

Table 4. Percentage of ethanol produced and glucose concentration

\begin{tabular}{cccc}
\hline Time, $\mathrm{h}$ & Specific gravity, v/v & Ethanol \% & Glucose Conc. \% \\
\hline 0 & 1.00 & 0 & 1.50 \\
0.5 & 1.008 & 0.8 & 1.35 \\
1.0 & 1.015 & 1.5 & 1.17 \\
1.5 & 1.023 & 2.6 & 1.12 \\
2.0 & 1.037 & 4.6 & 0.92 \\
2.5 & 1.050 & 7.5 & 0.66 \\
\hline
\end{tabular}

\section{Conclusion}

The experiment results in concluding that enough glucose is present in maize cobs and groundnut shells taken in a ratio 3:1. The acid concentration and temperatures optimised are $4.5 \mathrm{M} \mathrm{H}_{2} \mathrm{SO}_{4}$ at $80{ }^{\circ} \mathrm{C}$. A significant amount of ethanol is produced if glucose is fermented at specific conditions with Saccaharomyces cerevisiae (baker's yeast). Thus ethanol can be successfully produced using the agriculture by-products.

\section{Acknowledgement}

We are grateful the Principal, H.P.T Arts and R.Y.K. Science College, Nashik to provide us with the research facilities.

\section{References}

1. Ajani A O, Agarry S E, Agbede O O, J Appl Sci Environ Manage Dec, 2011, 15(4), 531-537.

2. Akpan U G, Kovo A S, Abdullahi M and Ijah J J, AU J Technol., 2005, 9(2), 106-110.

3. Gordon G B and Michael S, Food Science, 1979, pp 21, 37-97, Pergamon Int Popular Sci Series, Oxford, UK.

4. Benkun Q J, Xiangrong C, Fei S, Yi S and Yinhua W, Ind Eng Chem Res., 2009, 48(15), 7346-7353; DOI:10.1021/ie8016863

5. Megawati, Wahyudi B Sediawan, Hary Sulistyo and Muslikhin Hidayat, World Academy Science, Engineering Technology, 2010, 44, 135

6. Mohammad J Taherzadeh and Keikhosro Karimi, Int J Mol Sci., 2008, 9(9); 16211651; DOI:10.3390/ijms9091621

7. $\quad$ Cowling E B, Biotech Bioengin Symp Series, 1975, 5, 163-181.

8. $\quad$ Ghose T K, Adv Biochem Eng., 1956, 6, 39-76. 